\title{
EDUCOMUNICAÇÃO E SUSTENTABILIDADE: SAÚDE PSICOSSOCIAL EM CONTEXTO DE PANDEMIA DE DESINFORMAÇÃO
}

\author{
Rafael Gué Martini ${ }^{1}$
}

\begin{abstract}
Resumo: A pandemia da COVID-19 é acompanhada de uma profusão de desinformação que confunde e provoca sofrimento nas pessoas. Essa situação nos obriga a dedicar energia em dobro: na prevenção da doença e no constante embate de ideias motivado por informações controversas. Como se proteger dessa realidade e conseguir refletir de forma propositiva sobre o momento e situação que vivemos? Quais as relações que podemos estabelecer entre a cultura da (des)informação e a sustentabilidade? Que atitudes podem ser tomadas para melhorar nossa saúde psicossocial e nos fortalecer no enfrentamento dessa e de outras situações que podem surgir, em uma realidade de colapso socioambiental? Essas são algumas questões de fundo para o nosso diálogo sobre o campo da educomunicação, sua relação com a sustentabilidade, com as epistemologias do Sul e a necessidade de editarmos nosso mundo com consciência e ética.
\end{abstract}

Palavras-chave: Educomunicação. Epistemologias do Sul. Sustentabilidade. Pedagogia nativa. Objetivos de Desenvolvimento Sustentável (ODS).

\section{EDUCOMUNICACIÓN Y SOSTENIBILIDAD: SALUD PSICOSOCIAL EN EL CONTEXTO DE UNA PANDEMIA DE DESINFORMACIÓN}

Resumen: La pandemia de COVID-19 se acompaña de una profusión de desinformación que confunde y causa sufrimiento en las personas. Esta situación nos obliga a dedicar el doble de energía: en la prevención de la enfermedad y en el choque constante de ideas motivadas por informaciones controvertidas. ¿Cómo podemos protegernos de esta realidad y ser capaces de reflexionar a propósito sobre el momento y la situación en que vivimos? ¿Cuáles son las relaciones que podemos establecer entre la cultura de (des)información y la sostenibilidad? ¿Qué actitudes se pueden tomar para mejorar nuestra salud psicosocial y fortalecernos para enfrentar esta y otras situaciones que pueden surgir, en una realidad de colapso socioambiental? Estas son algunas preguntas fundamentales para nuestro diálogo en el campo de la educomunicación, su relación con la sostenibilidad, con las epistemologías del Sur y la necesidad de editar nuestro mundo con conciencia y ética.

Palabras-clave: Educomunicación. Epistemologías del Sur. Sostenibilidad. Pedagogía nativa. Objetivos de Desarrollo Sostenible (ODS).

\footnotetext{
${ }^{1}$ Doutor em Educação (UMinho). Professor efetivo na Universidade do Estado de Santa Catarina (UDESC). Endereço postal: Av. Madre Benvenuta, 2007 - Itacorubi - Florianópolis - SC CEP: 88.035001. E-mail: rafael.martini@udesc.br
} 


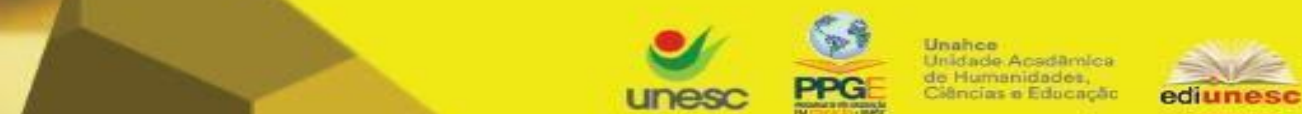

Criar Educação, Criciúma, v. 9, n², Edição Especial 2020.- PPGE - UNESC - ISSN 2317-2452

\section{Introdução}

Este artigo é alicerçado nas epistemologias do Sul, que considera vários tipos de conhecimento como válidos para discussão científica, em especial os saberes dos povos colonizados pelas nações do Norte. No entanto, o Sul não é um lugar geográfico, é uma metáfora para designar os conhecimentos elaborados pelos que lutam contra as injustiças sistêmicas causadas pelo capitalismo, colonialismo e patriarcado (SANTOS, 2018a). Nessa perspectiva, me considero um intelectual de retaguarda, vinculado às lutas ancestrais do continente americano. Essa conexão à nossa ancestralidade é um dos elementos da sustentabilidade.

Um artigo em tom de conversa, porque é o estilo mais próximo da oralidade, cuja valorização é um dilema a ser superado pela ciência moderna, alicerçada na linguagem escrita (SANTOS, 2018a). A valorização de uma linguagem científica mais áudio-scripto-visual (CLOUTIER, 1975) é condizente com uma sociedade do hipertexto que, em contextos de acesso à tecnologia, valoriza cada vez mais as múltiplas inteligências (FERRÉS; PISCITELLI, 2012). Essa linguagem pessoal, mais sensível e próxima, também promove a inteligência emocional (GOLEMAN, 1996), desconsiderada por muito tempo no espaço científico. Ela é evocada aqui na forma de uma razão sensível (HUERGO, 2010), ou de um corazonar, que inspira o sentimento de conexão do diálogo para produção de conhecimento coletivo emancipatório (SANTOS, 2018a). "O que pode o sentimento, não tem conseguido o saber"2, já nos diz a cultura musical latino-americana. E é nessa cultura artística de nosso continente, sensível ao tempo e espaço, que também apoio minhas reflexões, entendendo que a arte tem essa vocação para ser um tipo de ciência do senso comum, capaz de nos indicar os caminhos de novas utopias possíveis (SANTOS, 2018b).

No momento que atravessamos uma pandemia de saúde e também de desinformação (MACHADO, 2020), precisamos descobrir com urgência esses

\footnotetext{
2 Tradução nossa para "Lo que puede el sentimiento no lo ha podido el saber", trecho da música de Violeta Parra, cuja interpretação de Mercedes Sosa, com participação de Caetano Veloso, Chico Buarque, Milton Nascimento e Gal Costa, pode ser fruída no link: https://youtu.be/krEMw8E5ZAg
} 


\section{CRIAR EDUCAÇÃO}

Revista do Programa de Pós-Graduação em Educação - UNESC

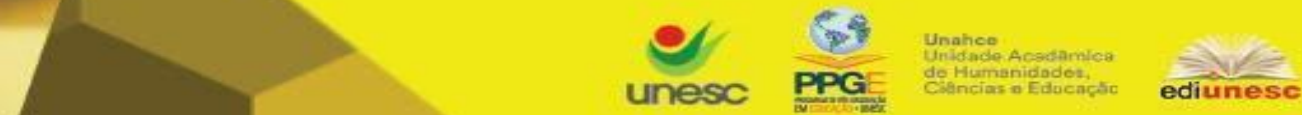

Criar Educação, Criciúma, v. 9, n², Edição Especial 2020.- PPGE - UNESC - ISSN 2317-2452

novos caminhos. Mas como fazer isso, se essas duas pandemias debilitam nossa saúde física e psicossocial, exigindo cuidados redobrados e atitude crítica permanente? A educomunicação e a sustentabilidade, associadas à arte e à ciência pós-abissal, podem nos ajudar a encontrar as forças para seguir lutando por nossas utopias possíveis. Discuto esses temas a partir de minha própria experiência, montando um mosaico cultural capaz de estimular as leitoras e leitores a movimentarem sua energia política paralisada.

Este texto é também hipertexto, que convida a navegar por referências áudioscripto-visuais e apresenta os sentimentos e as razões do seu autor. Ponto de vista traduzido por uma música, que a(o) convido a escutar e a dançar um pouco, para melhorar sua capacidade de concentração ${ }^{3}$ :

No Momento (100\%)

BNegão \& Seletores de Frequência

Os tambores anunciam pedem passagem alàáfia

Tá no conteúdo da mensagem

Alquimistas sonoros climatizando o ambiente

Trazendo uma energia diferente

Um batidão pra começar uma nova aurora recomeçar

Trago informação sonora pois a hora é agora

Eu disse, a nova e a velha escola

Chegam junto pra somar

A palavra real é o que se encontra aqui

Deixa o menino brincar, deixa a batida fluir

Tô chegando de novo trajeto definido

Prepare a pista de pouso no seu ouvido

Objeto sonoro não identificado

Não cabe na sua prateleira usual, no seu catálogo

3 Assista ao vídeo com a letra e dance um pouco no link: https://youtu.be/n8P6oop0Ffw 


\section{CRIAR EDUCAÇ̃̃̃O}

Revista do Programa de Pós-Graduação em Educação - UNESC

Criar Educação, Criciúma, v. 9, n², Edição Especial 2020.- PPGE - UNESC - ISSN 2317-2452

Música negra universal, interplanetária

Arte das ruas feita no fio da navalha

Tem que ter coragem, tem que ter o dom

Tem que ter amor, mas tem que ter razão

Tem que ter suor, mas tem que ter swing

Energia que nunca se extingue

$100 \%$ no momento, no momento $100 \%$

A revolução real a principal

É a de dentro pra fora

E não a de fora pra dentro

Bote isso de uma vez por todas

Dentro do seu pensamento

Tá na hora de evolucionar

De fazer diferente independente do repente

Independente da crença fazer a diferença

A sua micro parte é mais importante do que você pensa

Aprendizado sempre sente a pulsão da energia

Na pulsação do som a sensação a circulação ativa

Orgânica batida do beat do seu coração (LETRAS.MUS.BR, 2020a).

Ler a letra é muito diferente de ouvir a música e balançar ao seu ritmo. O conhecimento é absorvido também pela inteligência cinestésica da experiência. Exercício que queremos estimular além da simples leitura, para que você se conecte com as ideias usando vários sentidos. Essa busca por novas sensibilidades está na essência da educomunicação e da sustentabilidade. Ao tratar da contiguidade das práticas de educação e comunicação, a primeira etapa da educomunicação é a escuta profunda. Por isso, concentre-se $100 \%$ no momento e escute o que segue com todas suas inteligências. 


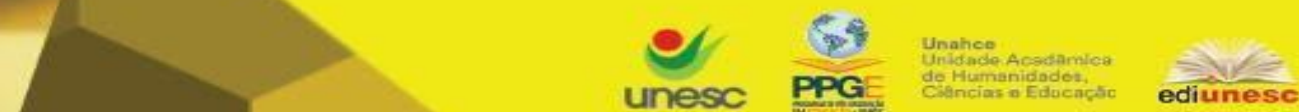

Criar Educação, Criciúma, v. 9, n², Edição Especial 2020.- PPGE - UNESC - ISSN 2317-2452

\section{Marco zero}

O ponto de partida desta reflexão sou eu, jornalista, professor, educomunicador e intelectual de retaguarda, que tem uma história e uma ancestralidade. Da ancestralidade herdei meu sentimento sobre a sustentabilidade e a educomunicação. E ela pode ser resumida em uma história revelada pelo meu avô, que muito contribuiu para meu processo de autoconhecimento.

Já perto dos meus 40 anos, meu avô contou que teve um tio que escolheu ser bugre ${ }^{4}$, ser índio, porque a sua mãe (avó do meu avô) foi uma índia que nunca aprendeu a falar o português. Lembrou que esse tio andava sem camisa, tinha um cabelo comprido (como eu já tive) e vivia sozinho nas matas. Era visto raramente e costumava fugir dos parentes quando encontrado casualmente. Mas, ao menos uma vez por ano ele saía de sua morada secreta nas matas para pedir ajuda à família, na cura de algum ferimento ou para renovar ferramentas. Um dia, o pai do meu avô, meu bisavô, resolveu vender suas terras em Bagé/RS. Iria se mudar com a família para a zona industrial que crescia perto da capital, Porto Alegre. Quando vendeu, negociou com o comprador para entregar as terras só após um ano. Queria contar para seu irmão índio o que tinha feito e dar a opção dele ficar ou viajar com a família. Meu avô lembrou, já olhando para o infinito, que, curiosamente, naquele ano seu tio não apareceu e nunca mais ninguém falou a seu respeito na família. Meu tio-bisavô bugre virou mais um índio esquecido.

Conto isso porque, duas gerações depois, como nas histórias familiares cíclicas do romance Cem Anos de Solidão (MÁRQUEZ, 1971), eu fui o membro da família que optou pelo sangue bugre. Sem saber da história do tio-bisavô, entrei em contato com várias etnias indígenas, fui morar em ecovilas e virei o integrante da família diferente da "normalidade" ocidental. Essa opção teve reflexos no meu pensamento e na minha visão científica do mundo, que compartilho com vocês neste momento.

4 Bugre é uma denominação dada a indígenas por serem considerados não cristãos pelos europeus (Wikipedia PT). 


\section{Educação, comunicação e sustentabilidade}

Como na letra de No Momento (100\%), que acabamos de ouvir, é preciso conectarmos a nova e a velha escola, para juntas somarem esforços na promoção das transformações sociais. Entendo que a nossa nova escola é a ciência ocidental e a velha o conhecimento pré-colonial. É neste último que me debruço a seguir, em especial à educação, à comunicação e à sustentabilidade.

Para ilustrar um fragmento desse conhecimento, cito os estudos de três autores que publicaram na coletânea Alfabetização Ecológica: A educação das crianças para um mundo sustentável, organizada por Fritjof Capra (2007). Ao analisar suas experiências junto a algumas etnias da América do Norte, Margolin (2007), Armstrong (2007) e Orr (2007) indicam alguns princípios de uma pedagogia nativa: pedagogia do lugar; foco na preparação do indivíduo de forma que capte o conhecimento que está no mundo; toda a sociedade é responsável pela educação de seus sujeitos; entendimento que a situação da aprendizagem faz parte do conhecimento adquirido; relatividade das certezas e a existência do insondável.

Alguns desses princípios tradicionais podem "apontar para áreas em que os nossos métodos e sistemas de educação são extremamente estreitos e perigosamente ineficientes" (MARGOLIN, 2007, p. 97). Eles também podem ser relacionados com os sete saberes necessários à educação do futuro, propostos por Morin (2000). No entanto, falamos de um conhecimento fruto de uma história de mais de 40 mil anos (MORISSAWA, 2001). Uma história de saberes com versões transmitidas oralmente em inúmeras etnias, mas que a ciência moderna ignorou. $(\mathrm{Re})$ Considerar estes aspectos inéditos do conhecimento dos povos oprimidos do Sul, pode nos indicar caminhos para a inovação (SANTOS, 2011). Assim, as epistemologias do Sul podem ser uma saída inovadora possível, se conectadas às lutas locais pela melhoria das condições de vida - pelo bem-viver ${ }^{5}$. Em meio a tanta (des)informação, precisamos reunir o conhecimento prudente para uma vida

\footnotetext{
5 "O conceito de sumak kawsay, em quéchua, ou o de suma qamaña, em aimará, foi incluído nas Constituições do Equador (2008) e da Bolívia (2009) para designar um horizonte emancipatório, ou seja, a ideia de um buen vivir que prescinde tanto do conceito de desenvolvimento quanto do de socialismo" (SANTOS, 2018a, p. 33)
} 
decente (SANTOS, 2000). Conhecimento que deixou de ser produzido pelos intelectuais de vanguarda para ser produzido pelos intelectuais de retaguarda, cujas lutas buscam transformar a atual sociedade abissal em uma sociedade pós-abissal (SANTOS, 2018a). Na atual sociedade abissal, as 62 pessoas mais ricas do mundo acumulam o equivalente a soma do que possuem os $50 \%$ mais pobres da população mundial (REUBEN, 2016). Na sociedade pós-abissal isso é inconcebível, e ela deve ser conquistada com luta por justiça cognitiva e socioambiental.

A educomunicação pode ser considerada uma epistemologia do Sul, que foi sistematizada no início do século XXI a partir dos estudos sobre as práticas educativas dos(as) comunicadores(as) populares ibero-americanos(as) (SOARES, 1999). Práticas vinculadas às lutas por justiça social e cognitiva, principalmente nos países latino-americanos. Inspirada nesses(as) intelectuais de retaguarda, seus princípios conversam com a pedagogia indígena, pois estão alicerçados no diálogo possibilitado pela tradução intercultural e na ecologia de saberes disponíveis em cada espaço-tempo.

A ecologia de saberes reconhece a co-presença de saberes diversos e a tradução intercultural possibilita estudar as afinidades, divergências e complementariedades entre eles, para otimizar a eficácia das lutas contra a opressão (SANTOS, 2018a). A possibilidade de nos conectarmos a qualquer tipo de tradição cultural, como eu me conectei à cultura indígena, e como os jovens hoje se conectam a diferentes tribos, torna a tradução intercultural um elemento fundamental na promoção do diálogo entre os saberes em ambientes escolares ou não-escolares. Isso é importante: a educomunicação não é aplicada apenas em escolas. Ela é um novo paradigma para promoção tanto da comunicação em espaços educativos, quanto da educação em espaços sociocomunicativos. Considero a necessidade de uma pedagogia perpétua (HUERGO, 2010), em um mundo em transformação constante, onde as práticas contíguas de educação e comunicação merecem atenção redobrada.

Talvez o aspecto mais relevante da educomunicação seja a promoção da religação semântica entre educação e comunicação. A separação dessas práticas, que muitas vezes operam em sentidos opostos, é motivo do que considero uma 


\section{Unesc PPGE}

Criar Educação, Criciúma, v. 9, n², Edição Especial 2020.- PPGE - UNESC - ISSN 2317-2452

esquizofrenia social (MARTINI, 2019). Por exemplo: após uma aula sobre igualdade de gênero, alunos da educação básica podem se deparar com uma propaganda de bebida alcóolica que objetifica a figura feminina. Essa objetivação é feita em uma peça publicitária, resultado do estudo de equipes profissionais, que fazem uso dos melhores recursos da comunicação behaviorista para ensinar determinado comportamento de consumo. Essa campanha publicitária patrocinada pelo 'mercado' pode ser considerada um plano de ensino, que dispõe de muitos recursos e pouca ética aplicados no alcance de seus objetivos de aprendizagem comportamental. Os índices de alcoolismo no Brasil e no mundo são um exemplo de como essas estratégias de ensino dão certo. A propaganda é um instrumento socioeducativo muito mais eficaz que a escola brasileira, sempre carente de planejamento continuado e recursos (SOUZA; NUNES, 2017).

A propaganda pode também ser classificada como um tipo de desinformação (fake news). Isso porque a distorção dos fatos, ou omissão de determinados aspectos, em detrimento da ênfase em outros, geralmente motivada por interesses não explícitos, é uma característica da desinformação e uma estratégia comum de marketing. A distorção acontece também em notícias que não são classificadas como falsas, pois muitos veículos de comunicação sacrificam a ética em nome do poder de quem os financia (CASTELLS, 2015). Como já nos alerta a arte popular: "eu não preciso ler jornais, mentir sozinho eu sou capaz" (LETRAS.MUS.BR, 2020b).

Castells (2015) comprova que falhamos em regular os meios de comunicação e que, apesar de termos a possibilidade da comunicação rizomática, o poder sobre as tecnologias e os canais que concentram a maioria da informação no mundo estão nas mãos de poucas corporações ${ }^{6}$. No geral, não consideramos, ou damos pouca atenção ao aspecto educativo da comunicação, principalmente quando ocorre fora do espaço institucional educativo. E é fora da escola que

\footnotetext{
6 Sobre a contribuição das corporações para as doenças psicossociais, recomendo o documentário The Corporation (ACHBAR; SIMPSON, 2003).
} 
acessamos a maior parte da informação ${ }^{7}$. Parte dessa informação chega até nós por canais, cujos objetivos desconhecemos ou, o que é pior, nem sabemos a fonte.

Esse é um aspecto relevante para nossa saúde psicossocial, pois se podemos dizer que somos fisicamente aquilo que comemos, em analogia, seremos psicológica, social e intelectualmente constituídos a partir das informações que consumimos, e dos pensamentos resultantes das reflexões sobre elas. Somos o fruto de nossas interações educomunicativas. E são essas interações que a educomunicação procura qualificar no âmbito dos ecossistemas educomunicativos - círculos de troca de cultura e conhecimento formados nos diversos espaços de convivência e interlocução. Esses ecossistemas são como a rede comunitária de aprendizagem permanente das aldeias nativas, onde a educação ocorria de maneira capilar e organicamente planejada.

Essa realidade abissal da comunicação, onde poucos detém muito poder sobre o que se fala ou se pensa no mundo, se converte hoje na pandemia de desinformação, também chamada infodemia. Se não soubermos transitar no oceano de possibilidades (des)informativas, se não mantermos o nosso foco naquilo que é o melhor para nós enquanto seres humanos e sociedade, corremos o risco de nos afogarmos nesse mar de conteúdos. Por isso, a Alfabetização Midiática e Informacional (AMI) é considerada fundamental pela UNESCO nesse contexto (WILSON et al., 2013). Sem ela não é possível o desenvolvimento socioeconômico e muito menos o desenvolvimento sustentável (PÉREZ TORNERO, 2015). A educomunicação é uma das vertentes regionais da AMI no Brasil, e aporta exemplos de boas práticas de inclusão digital inter e transdisciplinar.

Na situação de pandemia ficou mais evidente o abismo da exclusão digital na educação (MONIN, 2020). Percebemos mais a separação abissal entre os incluídos e os excluídos digitais e socialmente. Descobrimos que a pandemia não mata de forma tão indiscriminada quanto julgamos, pois atinge muito mais as populações menos assistidas (SANTOS, 2020). Para a educomunicação, 


\section{CRIAR EDUCAÇÃO}

Revista do Programa de Pós-Graduação em Educação - UNESC

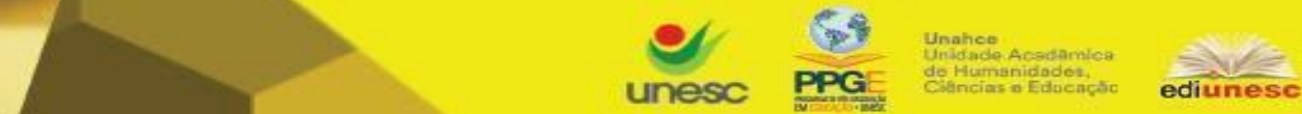

Criar Educação, Criciúma, v. 9, n², Edição Especial 2020.- PPGE - UNESC - ISSN 2317-2452

transformar essa sociedade abissal em uma sociedade pós-abissal, mais justa e solidária, é uma utopia possível. Ao menos já temos acesso aos saberes e experiências para isso. Nos falta essa religação dos aspectos educativos e comunicativos, desde nosso intelecto, para que a nossa ação educomunicativa possa alinhar sentimentos e pensamentos em torno de aprendizagens emancipatórias.

A emancipação é o motor das lutas sociais, e deveria ser também um objetivo em comum das universidades, que precisam retomar o compromisso ético da ciência com a transformação social. Essa (re)aproximação pode ressignificar o sentido do conhecimento acadêmico e resgatar sua credibilidade, abalada pela desinformação generalizada. O incentivo aos intelectuais de retaguarda, que não se restringem apenas a pensar criticamente sobre o mundo, promoveria a atitude crítica transformadora, em sintonia com os movimentos sociais (SANTOS, 2018a).

A ação educomunicativa é fundamentada na colaboração entre os seres que, mediados pelo mundo, produzem conhecimento (FREIRE, 1996). Ela inicia com o silêncio interior que qualifica a nossa escuta profunda, pré-requisito para modularmos o diálogo poético.

\section{O Constante Diálogo}

Há tantos diálogos

Diálogo com o ser amado
o semelhante
o diferente
o indiferente
o oposto
o adversário
o surdo-mudo
o possesso
o irracional
o vegetal
o mineral




\section{CRIAR EDUCAÇÃOO}

Revista do Programa de Pós-Graduação em Educação - UNESC

Criar Educação, Criciúma, v. 9, n², Edição Especial 2020.- PPGE - UNESC - ISSN 2317-2452

o inominado

Diálogo consigo mesmo

com a noite

os astros

os mortos

as ideias

o sonho

o passado

o mais que futuro

Escolhe teu diálogo

e

tua melhor palavra

ou

teu melhor silêncio.

Mesmo no silêncio e com o silêncio

dialogamos. (ANDRADE, 1977, p. 135-136).

No diálogo qualificamos a informação que, enquanto ato de dar forma à energia, é capaz de transformar a matéria que constitui a sociedade. Com duas décadas de estudos e aperfeiçoamento, a educomunicação tem promovido a atitude crítica, capaz de qualificar o acesso à boa informação. Ela se consolida como um novo campo com seis áreas de intervenção (MARTINI, 2019):

Figura 1 - Áreas da educomunicação

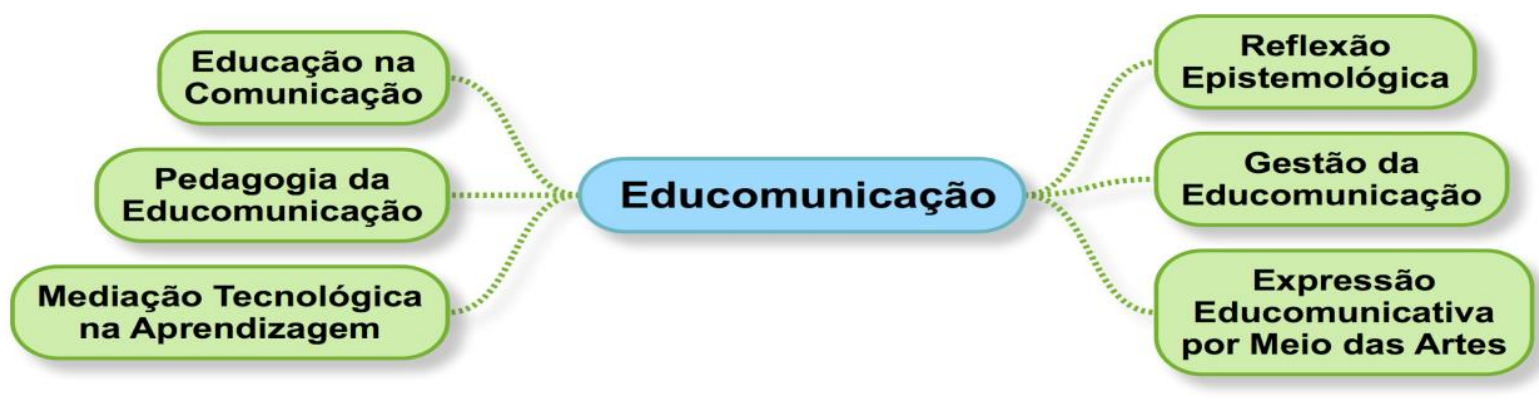

Fonte: Martini (2019). 
Educação na Comunicação: reflexão sobre o lugar dos meios e tecnologias de comunicação na sociedade e seu impacto em relação a autonomia dos sujeitos. As diversas modalidades de comunicação e sua modulação. Competência em mediações culturais, desenvolvimento do senso crítico e das inteligências múltiplas. A ética nas relações auto-inter-trans-subjetivas.

Mediação Tecnológica na Aprendizagem: reflexão sobre o porquê e como usar cada técnica específica na promoção da aprendizagem, objetivo comum às práticas de educação e comunicação. Considera a ecologia midiática no desenvolvimento de práticas de gestão democrática das tecnologias de informação e comunicação (TIC). Didática do uso das TIC nos ecossistemas educomunicativos. Expressão Educomunicativa por Meio das Artes: incentivo à auto-expressão e cocriação de arte por sujeitos e grupos. A arte não-canônica enquanto direito humano ao prazer da criação, que colabora com a saúde psíquica; e que é ponte transcendental de sentido entre ações educativas e comunicativas, com seus aspectos estéticos. Expressão dos sentimentos em relação a um novo mundo, como manifestação das utopias possíveis.

Pedagogia da Educomunicação: processo pedagógico instituinte que considera o potencial das práticas de educação e comunicação na promoção da emancipação dos sujeitos e de suas comunidades. Pedagogia da tradução intercultural por meio da tentativa do diálogo. Compreende os processos de comunicação na/pela educação e de educação na/pela comunicação. Aporte de metodologias, em especial a pedagogia de projetos, para o planejamento de Práticas Pedagógicas Educomunicativas (PPE). As PPE envolvem a articulação didática das áreas de Educação na Comunicação, Mediação Tecnológica na Aprendizagem e Expressão Educomunicativa por Meio das Artes.

Gestão da Educomunicação: prática da gestão da comunicação nos espaços educativos e da gestão intencional da educação nos espaços comunicativos. Planejamento da conexão entre o pensamento epistemológico e a ação pedagógica de forma ecossistêmica. Considera as condições socioambientais a partir das quais serão definidas as melhores ações para a criação e gestão de ecossistemas educomunicativos. Promoção de parcerias e ações em rede. 


\section{CRIAR EDUCAÇÃO}

Revista do Programa de Pós-Graduação em Educação - UNESC

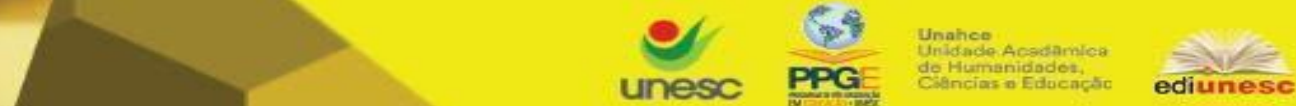

Criar Educação, Criciúma, v. 9, n²2, Edição Especial 2020.- PPGE - UNESC - ISSN 2317-2452

Reflexão Epistemológica: organização das condições para que o conhecimento surja, dentro de determinado contexto político e cultural. É levada em consideração na gestão do espaço e do tempo onde ocorrem as PPE. Representa a dinâmica de (re)construção epistemológica permanente, cultivada pelo(a) educomunicador(a)/professor(a)/mobilizador(a)-pesquisador(a) práxico(a), que sistematiza os conhecimentos em atitude crítica contra o desperdício da experiência. Essas seis áreas são articuladas na criação ou fortalecimento dos ecossistemas educomunicativos, enquanto espaços onde as práticas de educação e comunicação são cultivadas de forma saudável, genuína e emancipatória. A emancipação efetiva dos sujeitos é um dos horizontes utópicos das epistemologias do Sul, e está ligada a capacidade de cada um construir o seu próprio mundo a partir da reflexão e atitude críticas diante de um mundo que chega editado (BACCEGA, 1999). A circularidade dinâmica da ação cognoscitiva e dialógica promovida nos ecossistemas de educomunicação forma a palavramundo (FREIRE, 1988), a comunicação-mundo (MATTELART, 1994) ou se traduz no cimento social para a construção do mundo (MAFFESOLI, 2003).

Figura 2 - Ecossistema educomunicativo

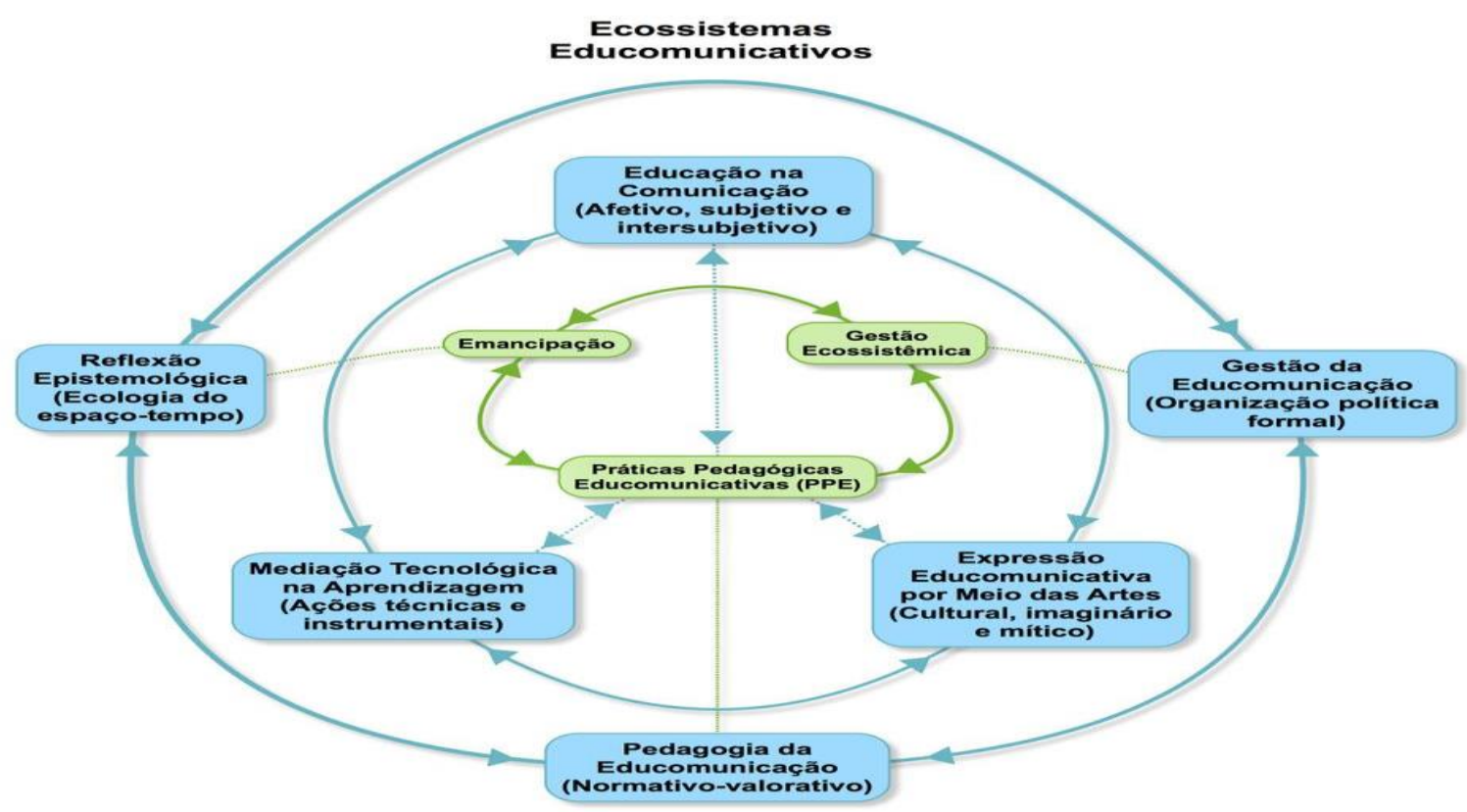

Fonte: Martini (2019) 


\section{CRIAR EDUCAÇÃO}

Revista do Programa de Pós-Graduação em Educação - UNESC

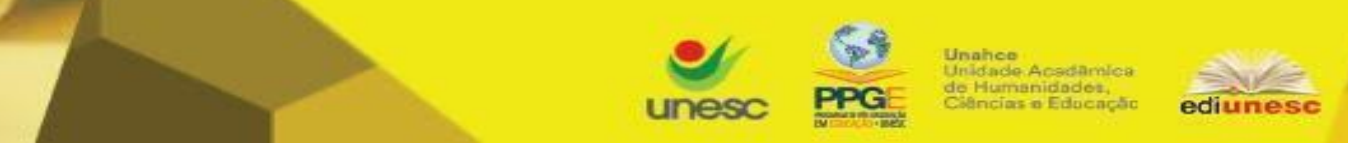

Criar Educação, Criciúma, v. 9, n², Edição Especial 2020.- PPGE - UNESC - ISSN 2317-2452

Nesse ecossistema, a reflexão epistemológica, em determinado espaçotempo, é orientada para a emancipação dos sujeitos. A ecologia de saberes disponível é operacionalizada pelo princípio ecossistêmico da gestão, que considera a pedagogia da educomunicação no planejamento e articulação das PPE, em espaços escolares ou não escolares. As PPE acontecem a todo o momento ao articularmos, de forma consciente ou inconsciente, nossa capacidade de mediação tecnológica (física), de educação na comunicação (simbólica) e de expressão artística (imaginária). Se nos inserirmos de forma mais consciente nos diferentes círculos de interlocução dos quais participamos, maiores as chances de ajudarmos a manter a nossa saúde psicossocial e a desses ecossistemas educomunicativos. No meu estudo doutoral sobre educomunicação, concebi uma imagem-síntese, materializada pela artista plástica Lu Gâmbaro: ${ }^{8}$

Figura 3 - Imagem-síntese da educomunicação

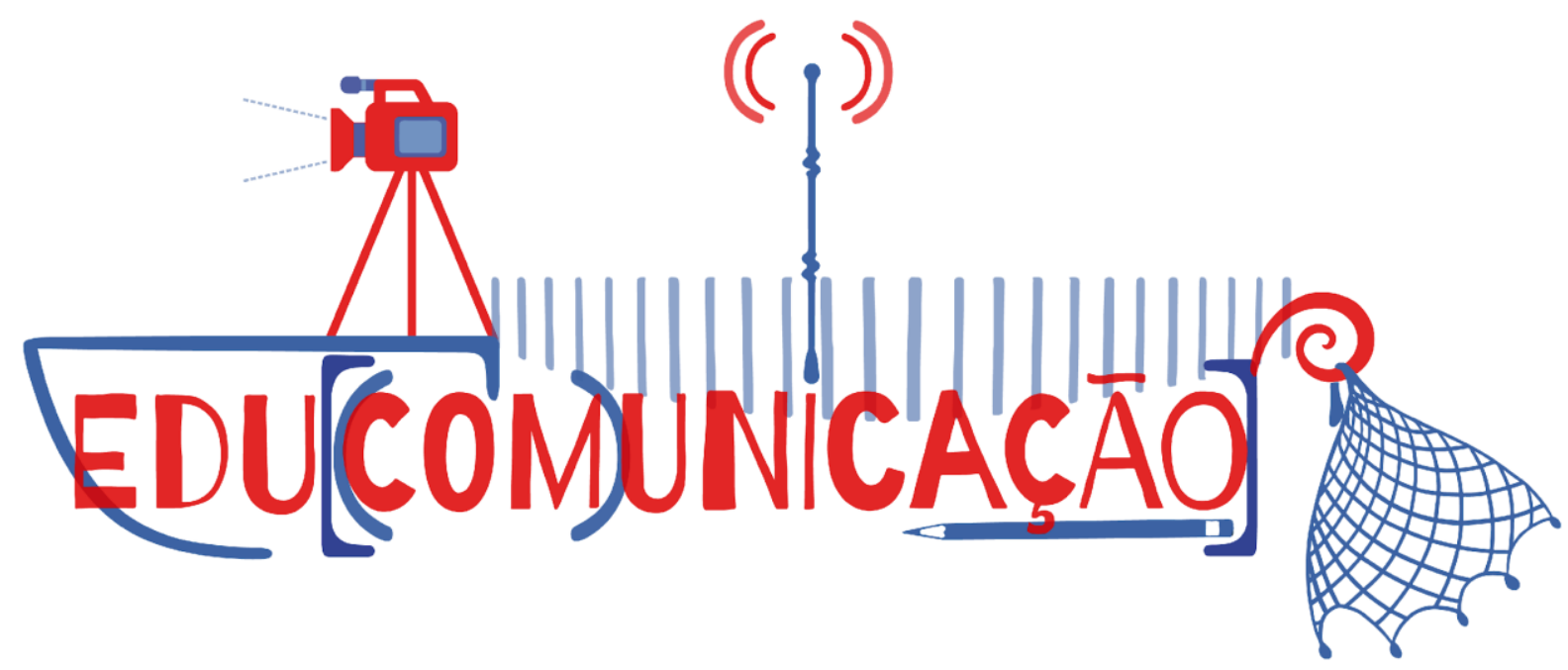

Fonte: Martini (2019)

8 O portfólio da artista pode ser apreciado no link: https://www.letrailustrada.com 
Nessa imagem-síntese, vemos que a palavra forma o acrônimo Educo com Comunicação-Ação. Eu me educo, para então educar com outros na prática da comunicação-ação, que dinamiza o processo de aprendizagem-ensino. Esse educar com respeita as múltiplas inteligências, simbolizadas pelo dial de rádio, o lápis e a câmera - as linguagens áudio-scripto-visuais. O dial do rádio indica também a modulação necessária para se estabelecer a conexão em uma mesma frequência, para que flua o diálogo. O conjunto forma um barco, que segue a direção do progresso em navegação de cabotagem: que se afasta cada vez mais do capitalismo, do colonialismo e do patriarcado, mas sem deixar de ver a margem do sistema, até que tenha segurança de aportar em uma sociedade pós-abissal. Uma epistemologia do Sul rumo ao corazonar. Como diz a música: "tem que ter amor, mas tem que ter razão" (LETRA.MUS.BR, 2020a). No leme a espiral indica a gestão ecossistêmica das ações educomunicativas, tanto no sentido do desenvolvimento para o interior de cada indivíduo, como para o exterior da sociedade. Pendurado no leme está uma rede que simboliza suas seis áreas de atuação. Com essa rede é possível capturar novos conhecimentos na ecologia de saberes da sociedade, sob a perspectiva da tradução intercultural.

A inversão sintática aprendizagem-ensino pode produzir mudanças semânticas importantes na educação. Por isso, a primeira etapa da educomunicação é a escuta profunda, para aprender sobre nossa equipe de aprendizagem, sobre os atores do nosso ecossistema educomunicativo. A equipe de aprendizagem pode ser formada por educandos, educadores, por pessoas da comunidade, organizações da sociedade civil, empresas, governos. Como na pedagogia nativa, toda a sociedade deve ser envolvida na educação, ou na educomunicação, para aproximar as pessoas da produção local de conhecimento.

\section{E qual a relação disso tudo com a sustentabilidade?}

A partir da reflexão sobre o espaço-tempo que vivemos podemos elencar e articular os saberes capazes de promover a nossa emancipação, e dos nossos colegas de convivência. O sujeito emancipado é aquele que edita o seu próprio 


\section{CRIAR EDUCAÇÃO}

Revista do Programa de Pós-Graduação em Educação - UNESC

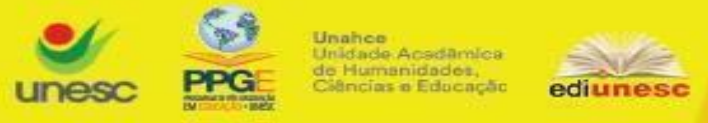

Criar Educação, Criciúma, v. 9, n², Edição Especial 2020.- PPGE - UNESC - ISSN 2317-2452

mundo, que escolhe seu percurso de formação consciente das influências que sofre de outras visões de mundo, que não são as suas, mas com as quais deve conviver com tolerância. "A revolução real a principal/ É a de dentro pra fora/ $E$ não a de fora pra dentro" (LETRAS.MUS.BR, 2020a), como ilustra a música.

Entre os saberes disponíveis sobre sustentabilidade, podemos nos alinhar e/ou alinhar nossas ações socioeducomunicativas aos Objetivos de Desenvolvimento Sustentável (ODS), enquanto parâmetros mundiais.

Figura 4 - Objetivos de Desenvolvimento Sustentável (ODS)

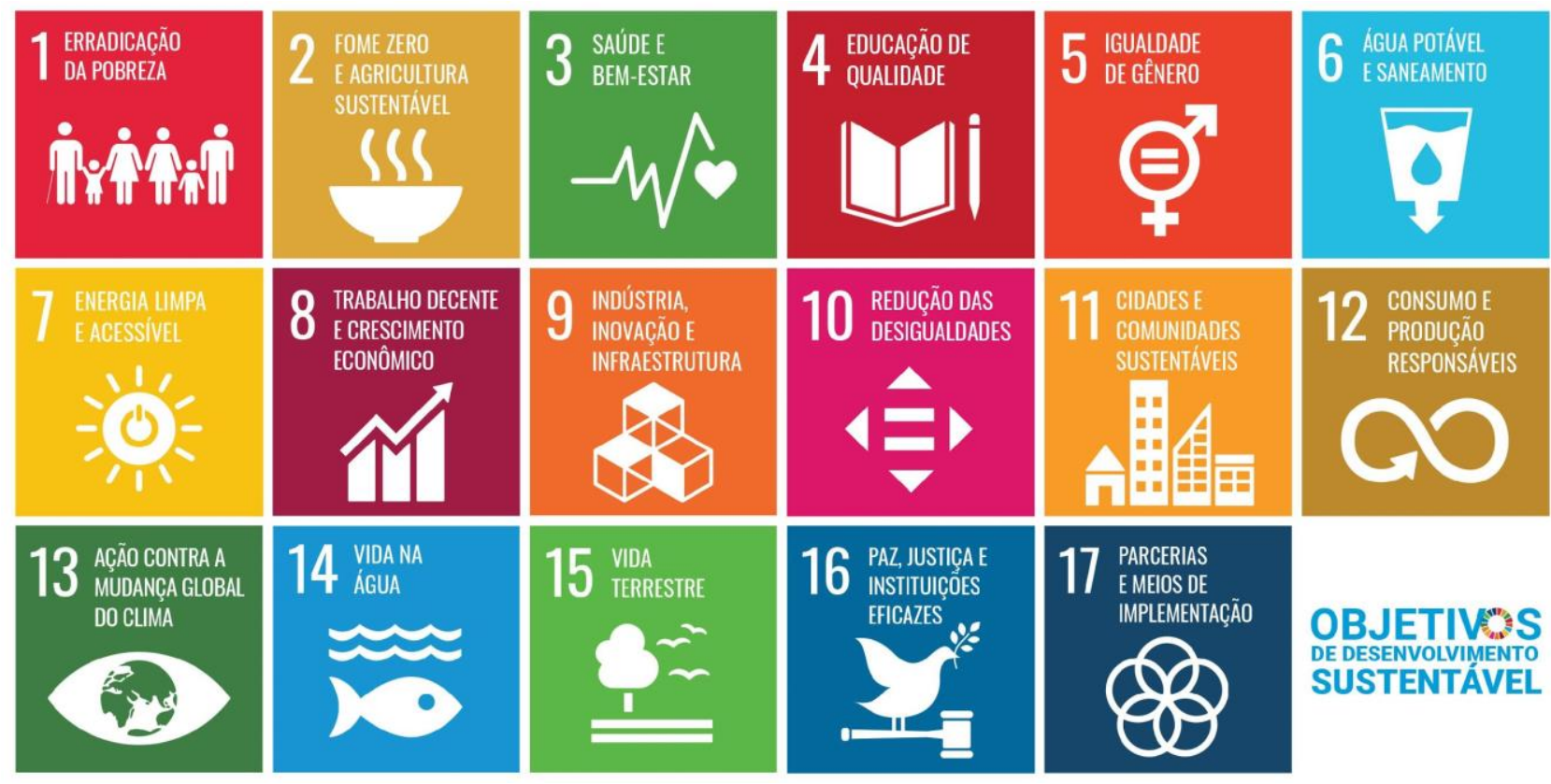

Fonte: Movimento Nacional ODS SC (2020)

Pensando na pedagogia do lugar, podemos fazer a ponte entre esses objetivos globais da Agenda 2030 da ONU (MOVIMENTO NACIONAL ODS SC, 2020) e nossas ações locais, em uma dinâmica glocal de interação em rede (SILVA, 2002). Esses objetivos possuem metas adaptadas à realidade brasileira e indicam um amplo leque de possibilidades de atuação, alinhadas com parâmetros universais 


\section{CRIAR EDUCAÇÃO}

Revista do Programa de Pós-Graduação em Educação - UNESC

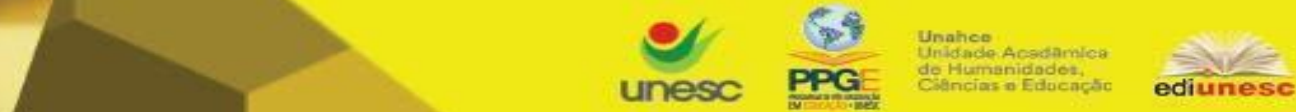

Criar Educação, Criciúma, v. 9, n², Edição Especial 2020.- PPGE - UNESC - ISSN 2317-2452

de qualidade de vida (SILVA; PELIANO; CHAVES, 2018). Os 17 ODS se agrupam em cinco pilares que facilitam o entendimento e aplicação de seus princípios.

Figura 5 - Cinco pilares dos ODS

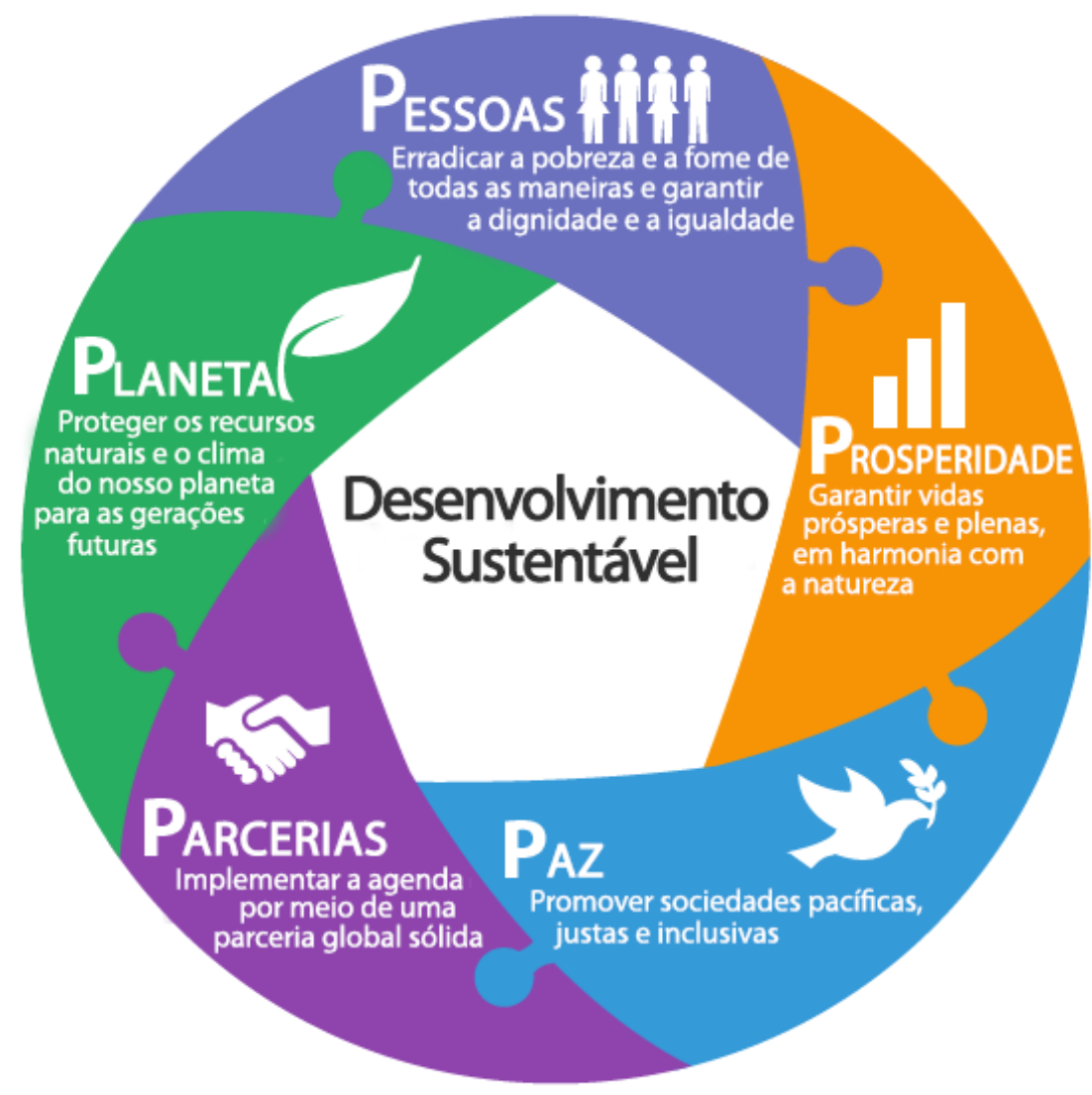

Fonte: Movimento Nacional ODS SC (2020)

A COVID-19 trouxe consequências em todos esses cinco pilares da sociedade, mas podemos tomar atitudes positivas ao entender melhor como articular educação e comunicação para qualificar o nível da informação que circula a nossa volta. Uma delas é atuarmos como curadores de conteúdo dentro de nossos ecossistemas educomunicativos escolares (em seus diversos níveis), midiáticotecnológicos (redes sociais e grupos virtuais) e sociocomunitários (família, amigos, trabalho). A nossa saúde psicossocial depende, em grande parte, desse cuidado 


\section{CRIAR EDUCAÇÃO}

Revista do Programa de Pós-Graduação em Educação - UNESC

\section{unesc PPGE}

Criar Educação, Criciúma, v. 9, n², Edição Especial 2020.- PPGE - UNESC - ISSN 2317-2452

com o tipo de informação e atitude comunicacional que desenvolvemos no cotidiano.

Além disso, ela determina nossa edição particular da palavramundo.

Praticamente, podemos nos vincular às perspectivas globais dos ODS para considerar melhor as pessoas, o planeta, fazer parcerias e promover a justiça e a paz desde o nosso campo de atuação. Em nossas redes de relacionamento podemos incentivar a partilha solidária da prosperidade.

$\mathrm{Na}$ educação escolar, as áreas da educomunicação e os parâmetros mundiais de sustentabilidade encontram eco na Base Nacional Comum Curricular (BNCC) (MEC, 2018). O que podemos observar em suas 10 competências gerais.

Figura 6 - As competências gerais da BNCC

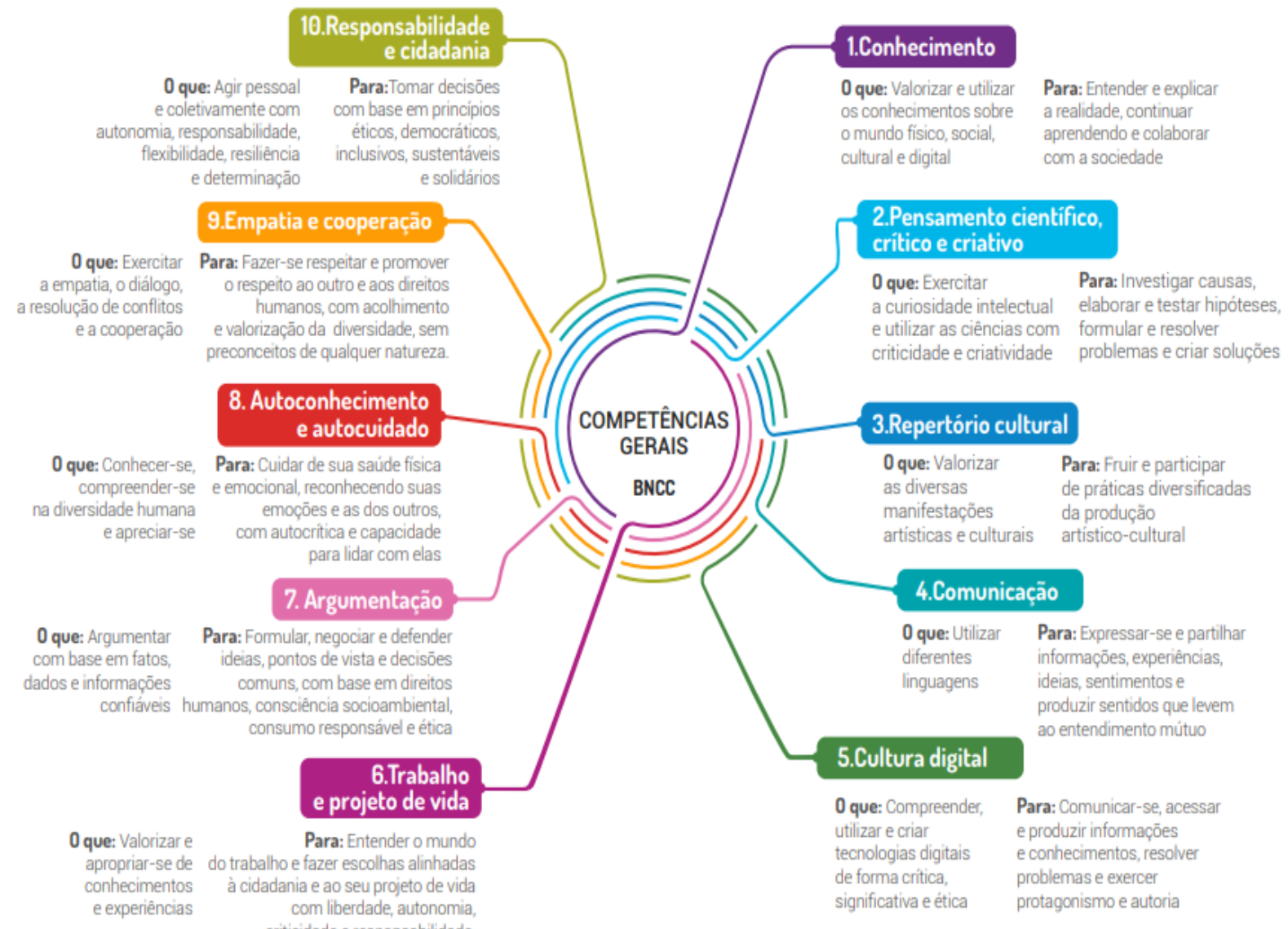

Fonte: Movimento Pela Base (2018) 
A educomunicação, alinhada com os ODS e com as perspectivas de sustentabilidade local, pode inspirar ações que ajudem a desenvolver essas competências nos professores e em seus alunos, na dinâmica da aprendizagemensino. São 07 áreas de intervenção, 17 objetivos e 10 competências que podem ser combinados em processos de educação com comunicação-ação, que ampliem a voz dos estudantes na escola, na família, no trabalho, nas redes sociais. Isso porque em todos esses espaços eles podem se tornar agentes educomunicadores, operando a dinâmica das práticas cognoscitivas e dialógicas na produção de saber inédito.

Nessa pedagogia perpétua, os estudantes, e cada um de nós, podem se tornar curadores de boa informação para a edição de um novo mundo. Podemos atuar localmente, junto com nossas comunidades, na construção coletiva do mundo utópico possível, desde nossa microparte, que "é mais importante do que você pensa" (LETRA.MUS.BR, 2020a). É nossa palavra que cria o mundo. Como na imagem simbólica ocidental do Gênesis bíblico, onde o poder criador está no verbo, a partir do qual se forma a matéria. No oriente, o hinduísmo fala do Om ou Aum como vibração sonora primordial de onde emana o universo. Essas são algumas relações culturais transcendentais entre a comunicação e a capacidade de criar novos mundos. Dentro da ecologia de saberes o conhecimento espiritual é válido e deve ser abordado, independente das instituições religiosas e, inclusive, para reduzir a influência negativa dessas instituições sobre a educação.

Em um vídeo produzido pelo Movimento Nacional ODS $\mathrm{SC}^{9}$, passo algumas dicas para alcançar as metas do ODS 4 - Educação de Qualidade para Todos: promover a Alfabetização Midiática e Informacional (AMI); promoção de parcerias da escola com a comunidade; trabalhador social e da educação agindo juntos; votar em políticos que não reduzam as verbas da educação; promover ações locais nas escolas com foco nos ODS (MOVIMENTO NACIONAL ODS SC, 2017).

Essas dicas consideram a tendência de um novo conceito de escola, caracterizado por um ambiente mais lato de aprendizagem, mais diversificado e

9 Assista o vídeo no link: https://youtu.be/XSD0qLc95is 


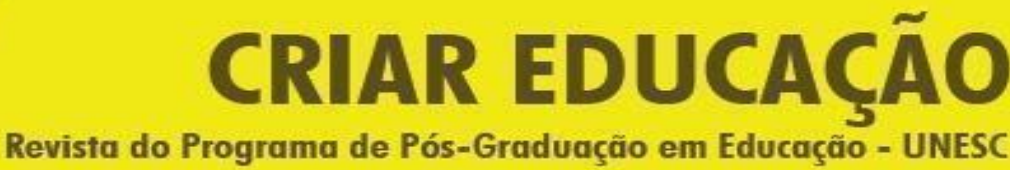

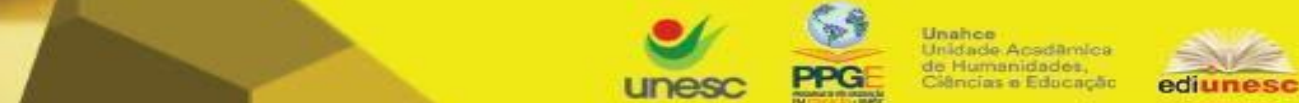

Criar Educação, Criciúma, v. 9, n², Edição Especial 2020.- PPGE - UNESC - ISSN 2317-2452

pulverizado pelo território (IE ULISBOA, 2017a), de forma a incentivar a pedagogia do lugar, como nos indica o pesquisador João Barroso:

\begin{abstract}
O local é onde emergem os problemas e se configuram as soluções. Neste processo cruzam-se várias tensões: entre controlo estatal e autonomia local; entre bem público e interesses privados; entre burocracia e profissionalismo; entre norma e projeto. Só a conexão entre os atores, a construção de comunidades de aprendizagem e a organização de redes colaborativas poderão tornar estas tensões criativas. Ao contrário da competição, da concorrência e do mercado que tornam estas tensões destrutivas. (IE ULISBOA, 2017a, 38:18).
\end{abstract}

Essa escola pulverizada no local, segundo Abílio Amiguinho (IE ULISBOA, 2017b), tende a fundir inovação educativa e social na parceria com os trabalhadores sociais, em um trabalho inter-relacional com equipes multidisciplinares e multiinstitucionais. Os problemas sociais que batem à porta da escola, exacerbados na pandemia, indicam que essa parceria é urgente. A melhoria da educação passa, obrigatoriamente, pela melhoria das condições socioambientais. Atuar na agência de formação institucional educativa com o objetivo de fortalecer a cultura local se torna uma ação fundamental, para a educação libertadora e dialógica. Assim, incentivamos o compromisso de toda a sociedade com a educação, pois a escola é apenas um dos espaços onde ela ocorre. A educação é o partido de todos nós, precisamos qualificar a cadeia de valor da educação desde a base e ampliar sua conexão com outros espaços não-escolares.

\section{Considerações presentes e futuras}

Em essência, importa assumirmos nossa perspectiva de curadores, capazes de religar educação e comunicação para evitar que a cultura da (des)informação resulte na sociedade da ignorância. Curadoria que inicia na esfera microssocial de nossos ecossistemas de educomunicação, onde podemos zelar pela nossa saúde psicossocial e de nossas relações com ética e alteridade. Os bons exemplos podem expandir em maré de mudança, desde o local até o global, na dinâmica glocal das redes. 


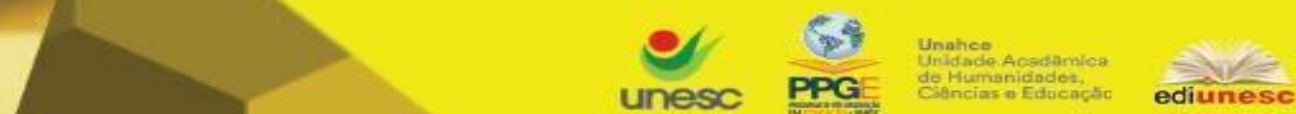

Criar Educação, Criciúma, v. 9, n², Edição Especial 2020.- PPGE - UNESC - ISSN 2317-2452

A quarentena provocada pela pandemia revela o pior, mas também nos apresenta alternativas possíveis e põe à prova nossa capacidade de se adaptar a novos modos de viver, inspirados no bem comum. No recrudescer da solidariedade vislumbramos outras formas de conviver, produzir e consumir com mais responsabilidade socioambiental (SANTOS, 2020).

Mas atenção! Não podemos nos auto-sabotar por uma improvável volta a 'normalidade' no imediato período pós-quarentena. Que essa situação nos mantenha alertas e dispostos a discutir as alternativas. Dentro da sustentabilidade, temos que nos ater a duas ideias fundamentais: a vida humana representa apenas $0,01 \%$ do total da vida no planeta; criar a condição para a continuação da nossa vida depende da defesa de toda a vida. (SANTOS, 2020).

Essas ideias sustentáveis começam em nós e, para mim, podem ser resumidas em um pequeno poema dos Provérbios do Inferno, de Willian Blake: "É suficiente! ou Basta" (BLAKE, 1993). Os que estão preparados para captar o conhecimento da pandemia, aprendem a se contentar com o suficiente, porque é o que nos basta para o bem viver. O melhor é perceber que, se nos mantermos assim, contentes com o suficiente, bastará a todos e à todas que habitam na Terra.

Com simplicidade e humildade convido todos e todas a se concentrarem em sua saúde e, com disposição, seguir acreditando no futuro. Mas acreditar com atitude crítica, para lutar contra os abusos do colonialismo, do capitalismo e do patriarcado. Como fez a então adolescente Anne M. Frank, que durante a Segunda Guerra Mundial ficou dois anos em confinamento, e nos deixou de herança esse belo aprendizado ${ }^{10}$ :

Para mim, é praticamente impossível construir a vida sobre um alicerce de caos, sofrimento e morte. Vejo o mundo ser transformado aos poucos numa selva, ouço o trovão que se aproxima e que, um dia, irá nos destruir também, sinto o sofrimento de milhões. $E$, no entanto, quando olho para o céu, sinto de algum modo que tudo mudará para melhor, que a crueldade também terminará, que a paz e a tranquilidade voltarão. Enquanto isso, devo me agarrar aos meus ideais. Talvez chegue o dia em que eu possa realizá-los! Sua Anne M. Frank (FOLMAN; POLONSKY, 2017).

10 Não deixe de ler o Diário de Anne Frank em quadrinhos, disponível em:

https://bit.ly/2UYBpii 
Seguirei lutando como uma garota pelos meus ideais!

\section{Referências}

ACHBAR (DIRETOR), M.; SIMPSON (PRODUTOR), B. The Corporation. Canada: Big Picture Media Corporation, 2003.

ANDRADE, C. D. DE. Discurso de primavera e algumas sombras. Rio de Janeiro, Brasil: Editora Record, 1977.

ARMSTRONG, J. C. Educação okanagan para uma vida sustentável: Tão natural quanto aprender a andar ou falar. In: CAPRA, F. (Ed.). . Alfabetização Ecológica: A educação das crianças para um mundo sustentável. São Paulo: Cultrix, 2007. p. 109-113.

BACCEGA, M. A. Comunicação \& Educação: do mundo editado à construção do mundo. Comunicação \& Informação, v. 2, n. 2, p. 176-187, 1999.

BLAKE, W. William Blake: Poesia e Prosa Selecionadas. 1. ed. São Paulo: Nova Alexandria, 1993.

CAPRA, F. (Ed.). Alfabetização Ecológica: A educação das crianças para um mundo sustentável. São Paulo: Cultrix, 2007

CASTELLS, M. O Poder Da Comunicação. Rio de Janeiro: Paz e Terra, 2015.

CLOUTIER, J. A Era de EMEREC ou a Comunicação Áudio-scripto-visual na hora dos self media. 2. ed. Lisboa: Instituto de Tecnologia Educativa, 1975.

FERRÉS, J.; PISCITELLI, A. La competencia mediática: propuesta articulada de dimensiones e indicadores Media Competence. Articulated Proposal of Dimensions and Indicators. Comunicar, v. XIX, n. 38, p. 75-82, 2012.

FOLMAN, A.; POLONSKY, D. O diário de Anne Frank em quadrinhos. 1. ed. Rio de Janeiro, Brasil: Record, 2017.

FREIRE, P. A Importância do Ato de Ler: em três artigos que se completam. 22 ed. ed. São Paulo: Cortez, 1988.

FREIRE, P. Pedagogia da Autonomia. 11ª ed. São Paulo: Paz e Terra, 1996.

GOLEMAN, D. Inteligencia emocional. Barcelona, España: Kairós, 1996. 
HUERGO, J. A. Una guía de comunicación/educación, por las diagonales de la cultura y la política. In: APARICI, R. (Ed.). . Educomunicacíon: más allá del 2.0. Barcelona: Gedisa Editorial, 2010. p. 65-104.

IE ULISBOA. AFIRSE 2017 | João Barroso. Arquivo de vídeo. Disponível em: $<$ https://www.youtube.com/watch?v=0mjTGdPiJR4\&list=PLs0ztMaFvMAaNo7_n0C $24 \mathrm{nst05} 5 \mathrm{dFmU6 \textrm {d }}>$.

IE ULISBOA. AFIRSE 2017 | Mesa Redonda 2. Arquivo de vídeo. Disponível em: $<$ https://www.youtube.com/watch?v=R63uVTliJ5k>.

LETRAS.MUS.BR. No Momento (100\%) - BNegão \& Seletores de Frequência. Disponível em: <https://www.letras.mus.br/bnegao-e-seletores-de-frequencia/nomomento-100/>. Acesso em: 5 jun. 2020a.

LETRAS.MUS.BR. Cowboy Fora da Lei - Raul Seixas. Disponível em: <https://www.letras.mus.br/raul-seixas/48307/>. Acesso em: 13 jun. 2020b.

MACHADO, D. Coronavírus também gera uma perigosa pandemia de desinformação. Folha de São Paulo, 2020.

MAFFESOLI, M. A comunicação sem fim (teoria pós-moderna da comunicação). Revista FAMECOS, n. 20, p. 13-20, 2003.

MARGOLIN, M. Pedagogia indígena: Um olhar sobre as técnicas tradicionais de educação dos índios californianos. In: CAPRA, F. (Ed.). . Alfabetização

Ecológica: A educação das crianças para um mundo sustentável. São Paulo, Brasil: Cultrix, 2007. p. 95-108.

MÁRQUEZ, G. G. Cem anos de solidão. 11. ed. Rio de Janeiro, Brasil: Editora Record, 1971.

MARTINI, R. G. Educomunicador como agente de integração das tecnologias de informação e comunicação na escola. Doutoramento em Ciências da Educação-Braga: Universidade do Minho, 2019.

MATTELART, A. Comunicação-mundo: História das Idéias e das Estratégias. Petrópolis, Brasil: Vozes, 1994.

MEC. Base Nacional Comum Curricular. Brasília: Ministério da Educação do Brasil, 2018. Disponível em: <http://basenacionalcomum.mec.gov.br/wpcontent/uploads/2018/06/BNCC_EI_EF_110518_versaofinal_site.pdf $>$. Acesso em: 5 set. 2018. 
MONIN, S. Quarentena e apartheid tecnológico: Brasil não fez da Internet objeto de política pública. Disponível em:

$<$ https://br.sputniknews.com/opiniao/2020042115485499-quarentena-e-apartheidtecnologico-brasil-nao-fez-da-internet-objeto-de-politica-publica/>. Acesso em: 13 jun. 2020.

MORIN, E. Os setes saberes necessários à educação do futuro. São Paulo; Brasília, DF, Brasil: Cortez; UNESCO, 2000.

MORISSAWA, M. A História da luta pela terra e o MST. São Paulo, Brasil: Expressão Popular, 2001.

MOVIMENTO NACIONAL ODS SC. 5 Dicas para alcançar o ODS 4 - Educação de Qualidade Para Todos. Disponível em:

$<$ https://www.youtube.com/watch?v=XSD0qLc95is\&feature=youtu.be $>$. Acesso em: 14 jun. 2020.

MOVIMENTO NACIONAL ODS SC. Portal do Movimento Nacional ODS Santa Catarina - Objetivos de Desenvolvimento Sustentável. Disponível em: <https://sc.movimentoods.org.br/>. Acesso em: 13 jun. 2020.

MOVIMENTO PELA BASE. Dimensões e Desenvolvimento das Competências Gerais da BNCCPorvir, , 2018. Disponível em:

$<$ http://s3.amazonaws.com/porvir/wp-

content/uploads/2018/02/28185234/BNCC_Competencias_Progressao.pdf>. Acesso em: 14 jun. 2020

ORR, D. W. Lugar e pedagogia. In: CAPRA, F. (Ed.). . Alfabetização Ecológica: A educação das crianças para um mundo sustentável. São Paulo: Cultrix, 2007. p. 114-124.

PÉREZ TORNERO, J. M. La emergencia de la alfabetización mediática e informacional Un nuevo paradigma para las políticas públicas y la investigación. Revista TELOS (Cuadernos de Comunicación e Innovación) -, p. 4-7, 2015.

REUBEN, A. $1 \%$ da população global detém mesma riqueza dos $99 \%$ restantes, diz estudo. Disponível em:

<https://www.bbc.com/portuguese/noticias/2016/01/160118_riqueza_estudo_oxfam fn>. Acesso em: 12 jun. 2020.

SANTOS, B. DE S. Para um novo senso comum: a ciência, o direito e a política na transição paradigmática. V.1. A crítica da razão indolente: contra o desperdício da experiência. São Paulo: Cortez, 2000. 
SANTOS, B. DE S. Epistemologías del Sur. Utopía y Praxis Latinoamericana. Revista internacional de Filosofía Iberoamericana y Teoría Social, n. 54, p. 17-39, 2011.

SANTOS, B. DE S. O fim do império cognitivo: a afirmação das epistemologias do Sul. Coimbra, Portugal: Edições Almedina, 2018a.

SANTOS, B. DE S. A arte e as Epistemologias do Sul: as linguagens da libertação. Aula Magistral proferida na Faculdade de Economia da Universidade de Coimbra. Anais...Coimbra: Informação Verbal, 2018b

SANTOS, B. DE S. A Cruel Pedagogia do Vírus. Coimbra, Portugal: Edições Almedina, 2020.

SILVA, B. A Glocalização da Educação: da escrita às comunidades de aprendizagem. O particular e o global no virar do milénio: Cruzar Saberes em Educação. Actas do $5^{\circ}$ Congresso da Sociedade Portuguesa de Ciências da Educação. Anais...Porto: Sociedade Portuguesa de Ciências da Educação, 2002

SILVA, E. R. A. DA; PELIANO, A. M.; CHAVES, J. V. AGENDA 2030: ODS - Metas Nacionais dos Objetivos de Desenvolvimento Sustentável. Brasília: Instituto de Pesquisa Econômica Aplicada - Ipea, 2018. Disponível em:

<https://www.ipea.gov.br/portal/index.php?option=com_content\&id=33895>. Acesso em: 14 jun. 2020.

SOARES, I. DE O. Comunicação/Educação: A emergência de um novo campo e o perfil de seus profissionais. Contato: Revista Brasileira de Comunicação, Arte e Educação, v. 1, n. 2, p. 19-74, 1999.

SOUZA, A. C.; NUNES, C. A. Decifra-me ou eu te devoro! - os fundamentos socioeconômico-culturais do modo de produção capitalista e suas implicações na história da educação e no trabalho educativo. Educação em Análise, v. 2, n. 1, p. 5-20, 2017.

WILSON, C. et al. Alfabetização midiática e informacional: Currículo para formação de professores. Brasília: UNESCO, UFTM, 2013. 


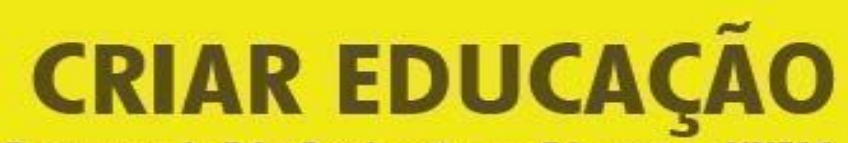

Revista do Programa de Pós-Graduação em Educação - UNESC

Criar Educação, Criciúma, v. 9, n²2, Edição Especial 2020.- PPGE - UNESC - ISSN 2317-2452

Recebido abril de 2020

Aprovado junho de 2020 